\title{
Box Jacking/Pushing Method for Tunnel Construction in Rock: Doha Metro, Gold Line Project
}

\author{
Spyridon Konstantis \\ skonstantis@qr.com.qa \\ Qatar Rail, Doha, Qatar \\ Spyros Massinas \\ smassinas@goldlinemetro.qa \\ ALYSJ JV, Doha, Qatar
}

\begin{abstract}
The case of a box pushing tunneling method in rock, on Doha Metro Gold Line project, successfully implemented to connect multiple entrance structures of Sport City station under a live traffic junction, in a heavy urban environment and under very shallow overburden is presented. Due to the size of the underpasses, the need to maintain uninterrupted traffic and the time-consuming utility diversions and reinstatement, the use of conventional NATM and Cut and Cover methods were assessed as either non-feasible or of high risk. The dimensions of the unsupported span, the encountered geotechnical conditions, the development of the settlements at road level and the box advance rate are presented.
\end{abstract}

Keywords: Tunnel; Box pushing; Rock; Ram forces; Advance rate

\section{INTRODUCTION}

The Doha Metro Gold Line Underground project is part of the rail network developed for the State of Qatar and was commissioned on 21 November 2019. The line crosses the center of Doha (see Figure 1) and includes 11 underground stations (Msheireb interchange station is constructed by others), underground stabling facilities, approximately $15 \mathrm{~km}$ of $7.1 \mathrm{~m}$ diameter twin tunnels excavated with 6 EPB TBMs and 24 cross passages. The project was awarded to ALYSJ Joint Venture, formed by Aktor of Greece, Larsen \& Toubro of India, Yapi Merkezi \& STFA of Turkey and Al Jaber Engineering of Qatar. Sport City station, one of the major Gold Line stations, is located next to a major highway junction along Al Waab Street and in close proximity to the Khalifa Stadium. It has been designed and constructed as an event station to serve major athletic events and thus cater for the increased ridership. The configuration of the station required pedestrian access to be provided to the station via subways passing under each of these roads and hence the construction of three pedestrian underpasses serving the three quadrants of the junction (see Figure 2).

The subway dimensions were selected to cater for the peak pedestrian traffic flows expected during sporting events and allow the installation of travellators and Mechanical, Electrical and Plumbing (MEP) equipment. The required internal dimensions and lengths of the subways were, Subway 1: $13.1 \mathrm{~m}$ width, $7.9 \mathrm{~m}$ height and $80 \mathrm{~m}$ length, and Subways $2 \& 3: 7.9 \mathrm{~m}$ width, $6.9 \mathrm{~m}$ height and $50 \mathrm{~m}$ length each. 


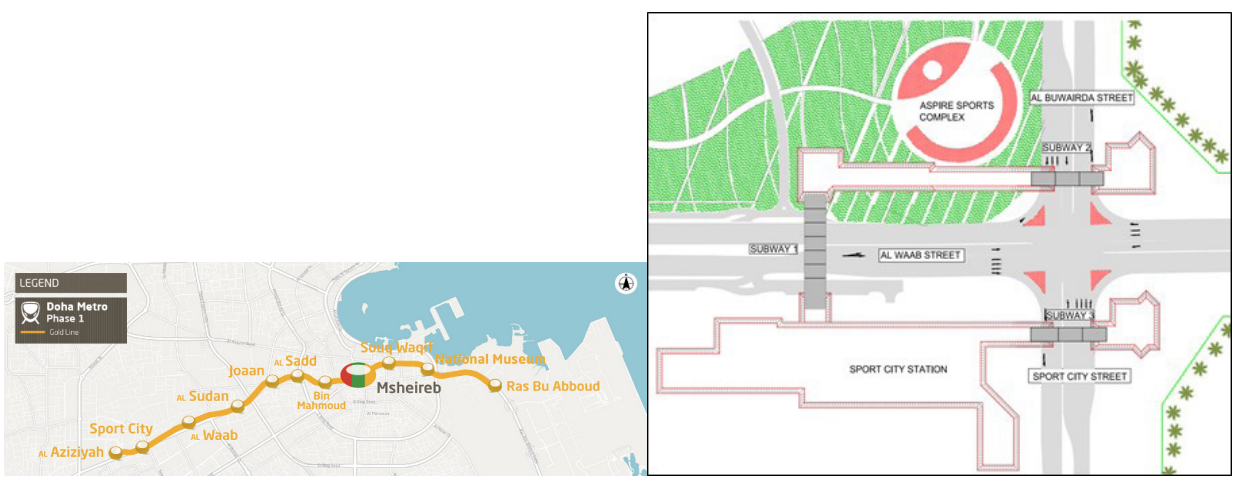

Figure 1: Gold Line overview map

Figure 2: Sport City station configuration

\subsection{Geology}

The geological model of the area was developed based on ground investigation boreholes. The profile consisted of made ground and residual soil deposits to a maximum depth of 2.6 to $3 \mathrm{~m}$ (locally in areas of existing utilities the depth was up to $4 \mathrm{~m}$ ), followed by the upper Dammam formation and the Midra Shale below the base of the subways. The Dammam formation consists of the Simsima limestone which can be met on site in different weathering conditions (from slight to moderate - extremely weak to very weak and moderately strong, light yellowish brown to greyish brown, dolomitic Limestone with pockets of silt/clay). The subways were constructed inside the moderate weathered Simsima limestone having a Young's modulus of $1 \mathrm{GPa}$ and a GSI range from 45 to 55. Figure 3 presents the geological profile along subway 1. The overburden height in Subway 1 varied from $3.5 \mathrm{~m}$ to maximum $5 \mathrm{~m}$, while under Al Waab street the mean overburden height was only $4 \mathrm{~m}$. In Subway 2 the overburden height was $6 \mathrm{~m}$ and in Subway 3 it varied from $4 \mathrm{~m}$ to $6 \mathrm{~m}$.

\subsection{Existing utilities}

Existing services were identified above the subways and within the zone of influence of the works, including TSE, foul sewer and potable water pipes, either INR, ductile iron or HDPE, ranging in diameter from 300 to $800 \mathrm{~mm}$ (see Figure 4). The identified utilities were documented, assessed for adverse impact, continuously monitored and protected when deemed necessary. In one case, a steel utility bridge was constructed to support a pipe, transversely crossing the underpass.

\subsection{Original design}

As per the original design proposed by the Contractor, the cut and cover construction method was to be adopted for each of the subways, which however inevitably involved implementation of temporary traffic management schemes, lanes closures and diversions. Due to the close proximity of the station to the highway junction, a preliminary traffic impact assessment report indicated that this would lead to significant traffic disruptions not only at the Sport City junction but also in the surrounding areas and in part due to other concurrent construction activities across the city. That would lead to non-compliance with the contractual requirement to 'KEEP DOHA MOVING' (Qatar Railways Company, Employers Requirements) and hence, alternative solutions were sought and considered 
to avoid traffic disruptions and public nuisance and disturbance. The first construction method considered was the mined tunnel construction with conventional method (SCL/ SEM/NATM), however this was excluded as an option due to geometrical constraints arising from the large size of the subways and the limited available ground cover (very low overburden height) of soil type formations. From a geological and geotechnical perspective, the underpasses would be excavated and constructed inside weathered and relatively weak limestone rock overlaid by made ground.

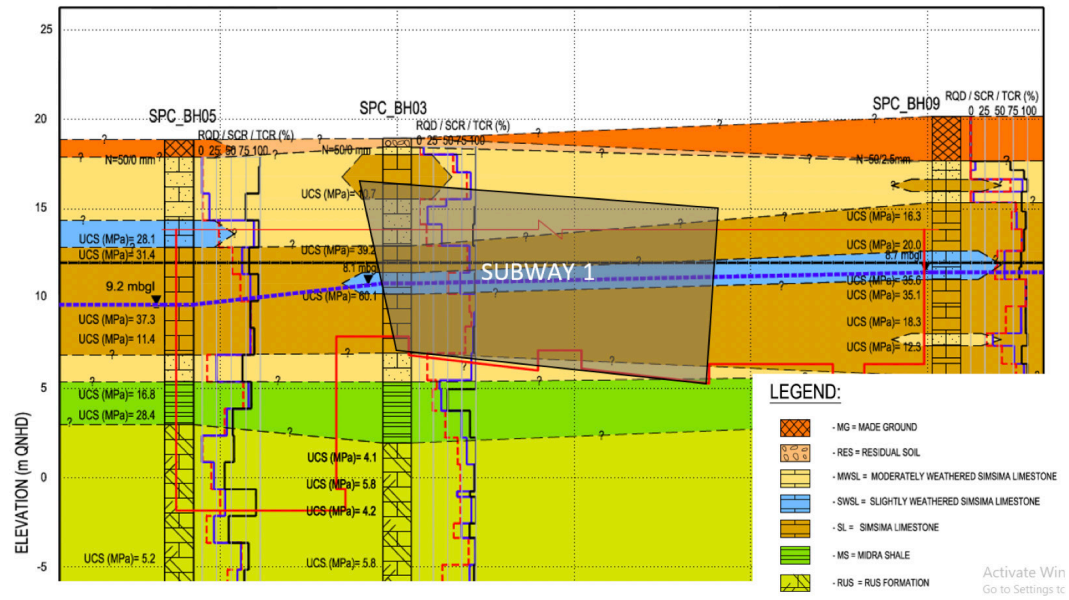

Figure 3: Geological profile along subway 1

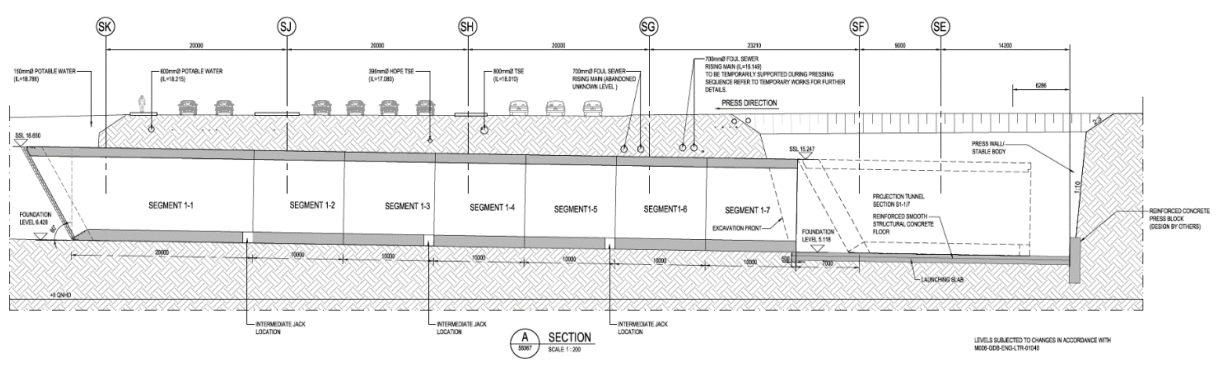

Figure 4: Longitudinal section of Subway 1 with utilities location

Design and construction related issues aside, a major constraint and decisive factor was also the very tight construction schedule with limited available activities duration and float. Following a rigorous comparative risk assessment, the box jacking/pushing method was selected for the three subways passing below the highways (see Figure 2), which was awarded by the Contractor to a specialist subcontractor, Petrucco of Italy. Most if not all of the recorded box jacking/pushing cases are in soil formation and therefore the prevailing ground conditions (weak rock) in Sport City resulted in a unique construction method (excavate and push rather than push inside the ground and excavate inside the box), a first in the Middle East region, and as per authors' knowledge unique worldwide. In the following, the design scheme and construction sequence is presented, together with detailed design inputs for the jacking loads, settlement analysis, ground 
stability and structural analysis. In addition, the challenges faced during construction are also presented, including settlement protection of utilities, effects of over excavation and lessons learnt. The subways were successfully constructed between 2016 and 2017 with no disruption to traffic.

\section{DESIGN SCHEME AND GENERAL CONSTRUCTION SEQUENCE}

The three jack box tunnels, consisting of a number of precast reinforced concrete segments, were constructed in launch pits positioned in such a way that they were laid either along the alignment of the pedestrian walkway or were located within the subway entrance profile. This allowed the excavation space to be re-used and reduced the construction programme. During construction of the jack box subways, several segments were under construction simultaneously to reduce the total construction time. The segments were constructed sequentially and once completed, they were laterally jacked to the excavation face from where they were jacked into their final position (see Figure 5).

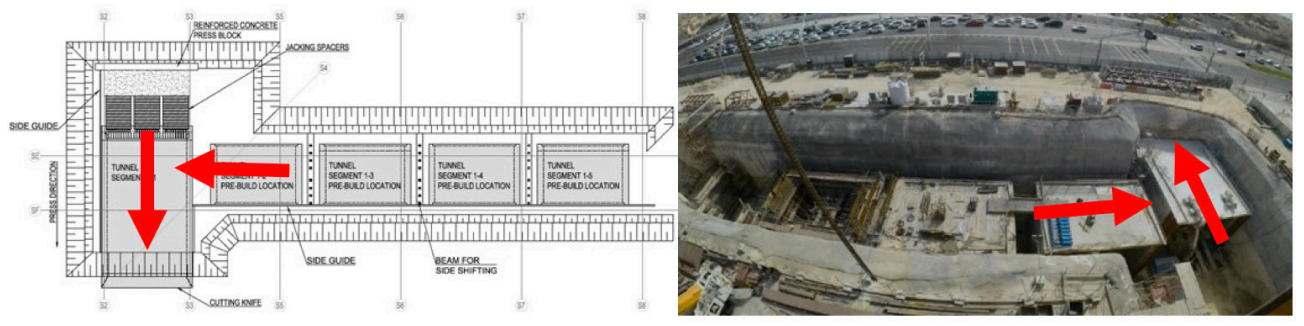

Figure 5: Subway 1 construction: Segments layout drawing and Box jacking sequence (left) and aerial photo (right)

A summary of the construction sequence is as follows; 1) Excavate the launch pit to formation level and cast smooth concrete slab; 2) Cast first segment, reaction block and jack installations; 3) Excavate front face, lay sand on the base, shotcrete for any over excavation, and begin pushing sequence. Install ground beams as required to control alignment. Excavation was limited to $500 \mathrm{~mm}$ advancement length under the existing utilities in close vicinity with the box roof (until the segment overcame the full width of the utility pipes trenches). For more competent rock (see Figure 6) the excavation length increased up to $1 \mathrm{~m}$ and even to $2 \mathrm{~m}$. Over excavation was limited up to $20 \mathrm{~mm}$ when underpassing critical utilities, while above $50 \mathrm{~mm}$, shotcrete was applied before jacking. The face was excavated in phases before the next push, i.e. first the left and right parts and then the middle part which acted as a buttress (see Figure 7). Above steps were repeated; 4) Concurrent with first segment pushing, next segments were cast in the launch pit (see Figure 5); 5) Dismantle the jack array and slide laterally the next segment into position; 6) Reassemble the jacking array and begin the pushing sequence again. Steps were repeated until all segments were in the final position; 7) Cast box segment stich details; 8) Connect jack box subways to cut and cover station box and entrance structures. 


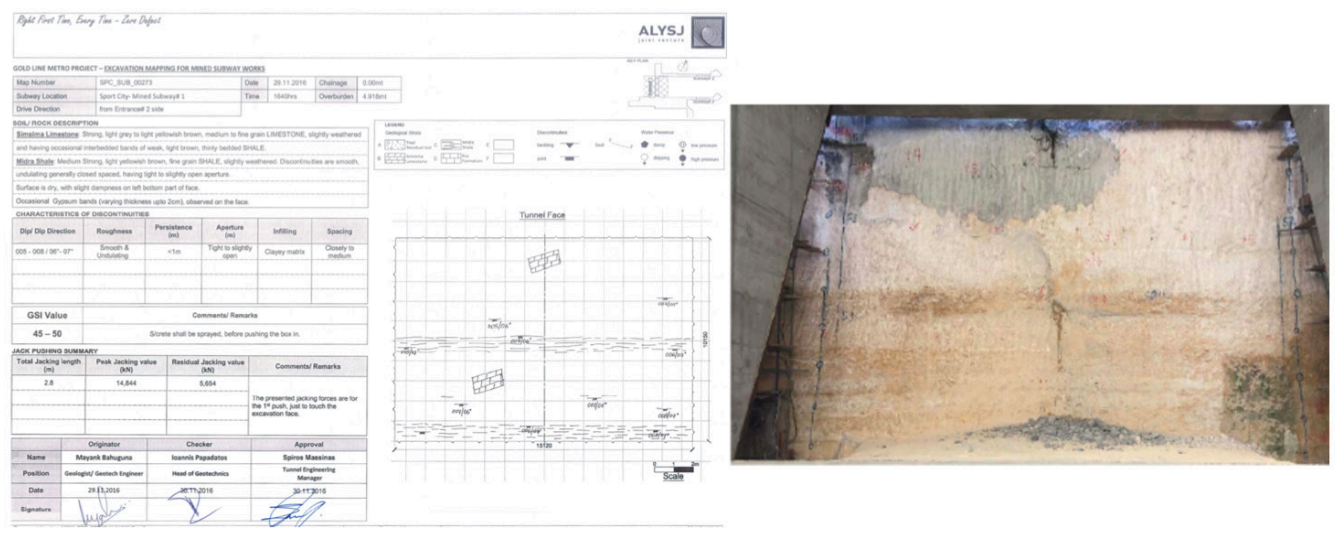

Figure 6: Example of Face Mapping on Subway 1 for good rock conditions at the face

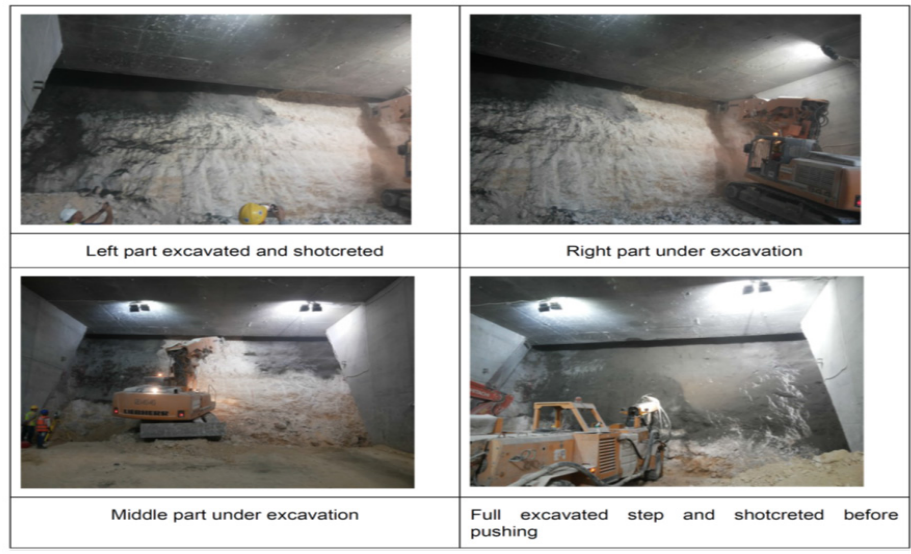

Figure 7: Excavation sequence with shotcrete application to control over-excavation

\section{CONCRETE SEGMENTS DETAILS}

A major risk associated with the box pushing method is the potential for the box segments to be "trapped" due to the friction between the segments and ground, resulting in major impacts for the construction programme. Several measures were adopted to reduce this risk. Firstly, intermediate jacks were located between the box segments to allow the segments to be pushed individually (intermediate jacking stations every $20 \mathrm{~m}$ of underpass), reducing the loads and providing construction flexibility. The adjoining segments were also connected with $20 \mathrm{~mm}$ thick steel plates anchored into the segment with shear studs that could slide freely to open and closed positions (see Figure 8). The steel plates acted to restrain the segments from becoming misaligned and in addition assisted to avoid the segments jack-knifing.

A protection shield (see Figure 9, left) all around the front part of the first segment was constructed. This shield was designed to reinforce the front part against any falling rocks and accidental damages during the excavation. The shield arrangement allowed the construction teams to reach the whole perimeter of the excavation using hammers or mills or use small hand-hammers to refine the excavation profile. It was also designed to be easily removable and allow the teams to reach the structural couplers that were 
positioned underneath it without damaging or cracking the concrete structure.

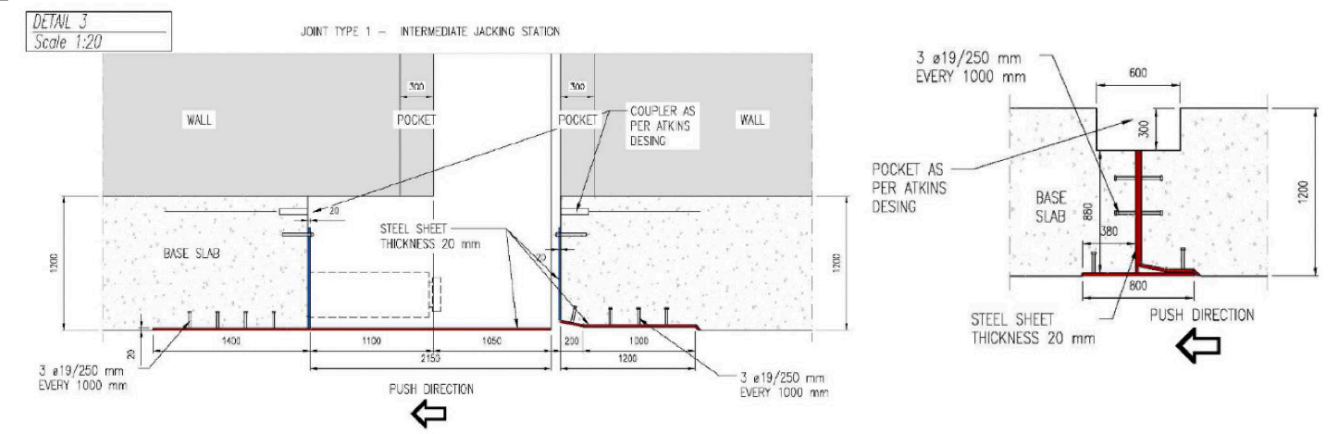

Figure 8: Detailed arrangement for intermediate (left) and non-intermediate (right) jacking station

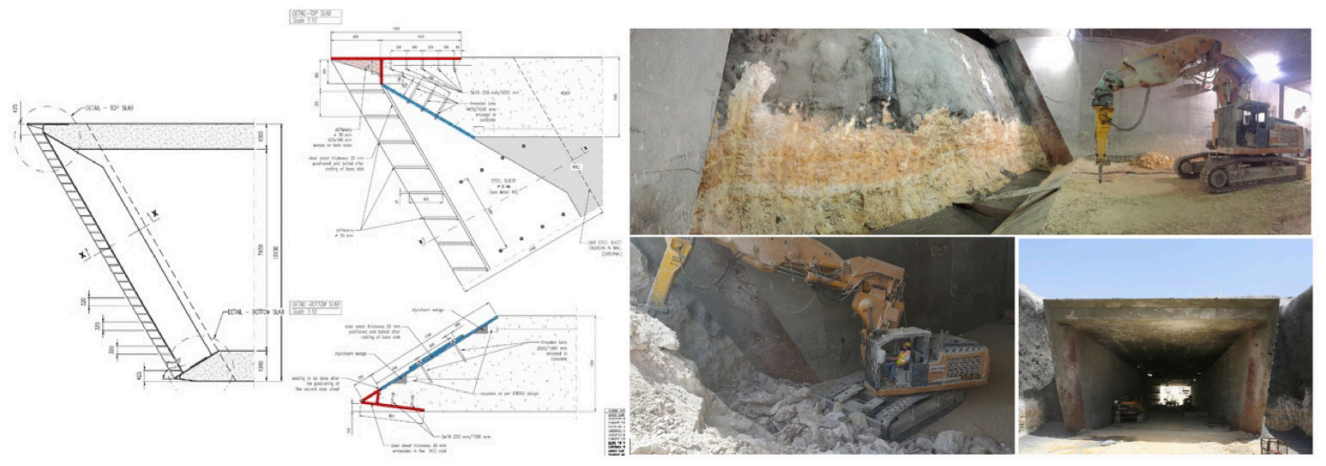

Figure 9: Detailed arrangement of front shield (left) and photographs during construction (right) (Inside subway 1, top; final breakthrough, bottom; protection shield is visible at the front part)

\section{JACKING LOADS}

In order to minimize or even eliminate the risk of the segments being 'jammed' during the pushing operations (which would have very adverse impact on the construction progress), it was considered necessary to be conservative with the determination of the maximum capacity for pushing the segments and hence ensure that there would be sufficient jacking force with available safety margin. This was achieved by calculating the maximum jacking forces based on the frictional resistance of the ground applied to the roof, walls and base slab i.e. the total perimeter. Based on the experience presented by Petrucco, a coefficient of friction of 0.5 was adopted and applied. The front segment $\mathrm{S} 1$ was placed $3 \mathrm{~m}$ away from the entry point into the ground in order to verify the adopted friction coefficient. The hydraulic jacks were grouped and housed together in steel cradles and positioned to apply loads only to the base slabs. Figure 10 presents the recorded forces of the jacking rams (main rams with counteraction on the reaction wall and intermediate rams between the segments every $20 \mathrm{~m}$ ). The 'saw' scheme of the recorded values is due to overcoming the friction before sliding of the segment in each jacking step. 


\section{DETAILED DESIGN OF THE CONCRETE SEGMENTS}

The relatively high ground stiffness, compared to the more softer ground conditions where the jack box method is traditionally used, meant that the construction methodology and design would have to be modified. Firstly, it would not be possible to push the cutting knife of the first pushed segment into the ground during the pushing sequences. The excavation had therefore to take place in advance of the cutting knife and be larger than the box perimeter to facilitate the jack box pushing sequence. The over excavation could have adverse impact on the surface settlements and it was intended therefore to be limited. The proposed solution was to limit the advance excavation and to use shotcrete to fill any over excavations around the perimeter. This sequence of events required a design verification that the ground would be self-supporting and the magnitude of the surface settlements within acceptable limits. In addition and due to the use of shotcrete for over excavation limitation, additional design verifications had to be carried out for the worst case of shotcrete bonding to the box perimeter. A 3-D solid element soil-structure interaction Finite Element Model (FEM), incorporating all construction sequences, was adopted in the commercially available software LUSAS (see Figure 11, left). A shear strength reduction analysis was adopted to verify the factor of safety of the cutting face slope with a factor of safety of 1.25 . The results of the analysis proved that a 300 to $500 \mathrm{~mm}$ excavation advancement would provide adequate safety and limit settlements to within acceptable limits. For face stability, a 60 slope was recommended to be adopted, however it was also proven through the analysis that a 75 slope could also be safely adopted, to allow for construction tolerances and provide a safe minimum angle.

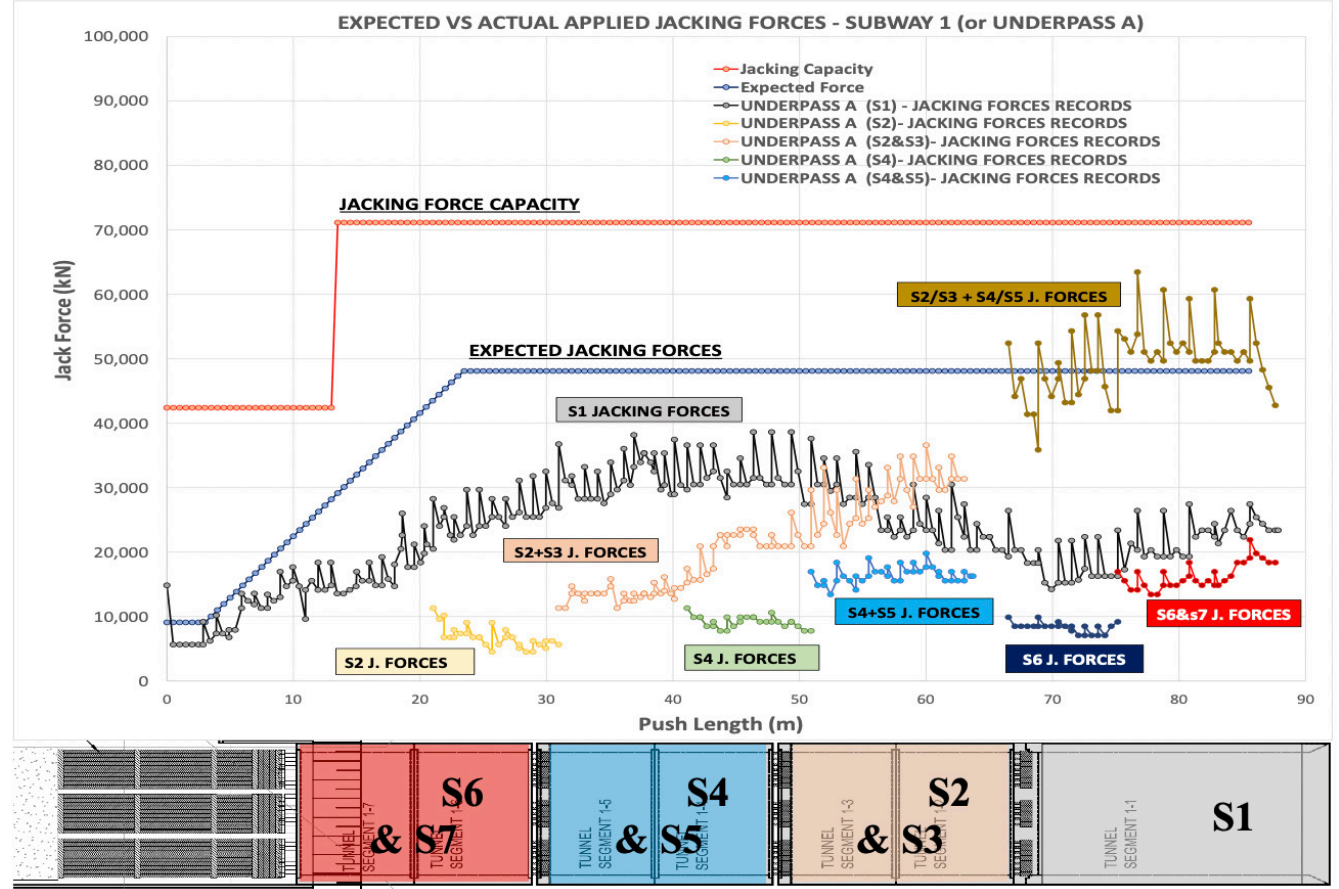

Figure 10: Hydraulic jacks - Designed vs Actual applied forces in each jacking station 

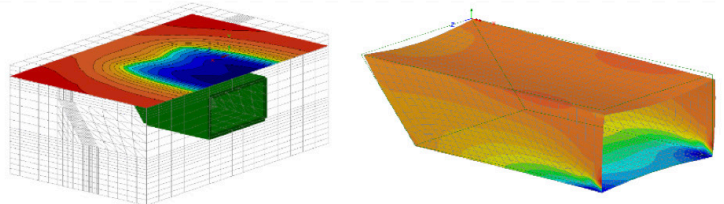

Figure 11: Soil-structure interaction model showing vertical displacement contours (left), and, 3D shell element model showing axial stresses induced by jacking loads (right)

A series of numerical analysis was carried out with a variety of geotechnical parameters to create an envelope of the stress state in the concrete segments. For example the case of no lateral ground loads due to over excavation has been examined. This load combination was critical for the design of the roof slab to limit the crack widths within contract's specifications. To cover the case with full lateral loads due to grouting through grout sockets embedded in the walls, roof and base slabs, another load combination with a $\mathrm{K}=0.9$ was adopted. It is noted that contact grouting was applied in the perimeter only after the final breakthrough. To verify the global behavior of the box segments subjected to the maximum capacity of the jacks, a second 3-D model was built, adopting shell elements (see Figure 11, right). The loads were applied to the base slab and the frictional resistance to the perimeter of the model. Subsequent stress checks were made to ensure that the section did not exceed the allowable tensile capacity of the concrete and bursting reinforcement was added to each base slab (EN 1991-1-2004, Design of Concrete Structures). As mentioned above, additional design verifications were carried out for the worst case of shotcrete bonding to the box perimeter. The minimum concrete cover to reinforcement was $55 \mathrm{~mm}$ as required for durability on the external face. An additional $30 \mathrm{~mm}$ was provided as sacrificial concrete for abrasion based on previous experience, equating to a total cover of $85 \mathrm{~mm}$.

\section{INSTRUMENTATION AND MONITORING (I\&M)}

Due to the criticality of the box pushing operations being continuously carried out under a busy carriageway and live utilities with limited overburden, a robust real-time instrumentation and monitoring regime was installed, comprising level points installed near utility trenches, extensometers and asphalt road points (see Figure 12, left).

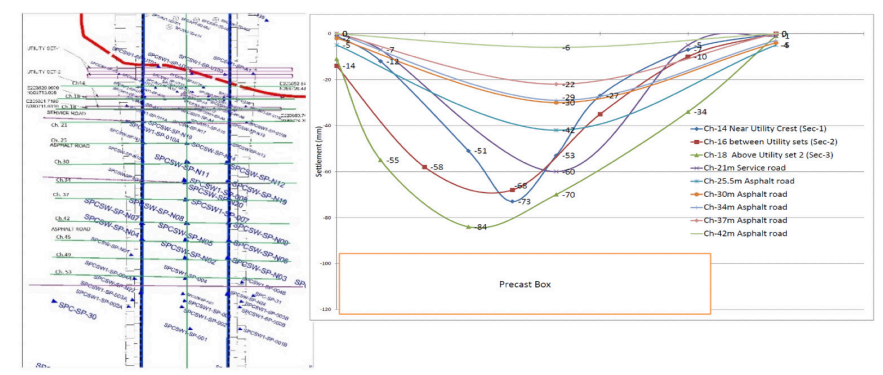

Figure 12: I\&M Plan with settlement section lines (left) and measured surface settlements transverse to the box pushing operation (right) - subway 1 
Prior to the commencement of the box pushing operations, it was identified through site surveys and determined from the analysis, that the first set of utilities to be encountered located below the service road (see Figure 4) would require appropriate protection as diversion was not an option due to schedule constraints. Further investigations and liaison with the utility owners, revealed that only one set of utilities was live and had to be protected. It was consequently decided to protect these live utilities and suspend them from a utility steel bridge, given also the poor compaction level of the trench backfill identified through site investigations. As foreseen and anticipated (see Figure 12, right and Figure 13), the backfill of these utilities trenches exhibited increased settlements mainly attributed to the low rock cover in this area and possibly the dynamic compaction of the backfill during the hammer and roadheader excavation. However, no adverse impact was experienced by the live utilities protected by the steel bridge.

From the ground settlement results, it can be seen from the section lines above the asphalt road where the rock cover was in the order of 3-4 $\mathrm{m}$ (excluding the sections above the utilities and adjacent to these due to the proximity interaction) that the overlying rock exhibited a 'bridge' response with a remarkable deformation line similar to a loaded 'restrained beam'. In the very limited cases where ground deformations exceeded the allowable limits or caused damage to the surface areas and paved roads, those were reinstated by ALYSJ JV.

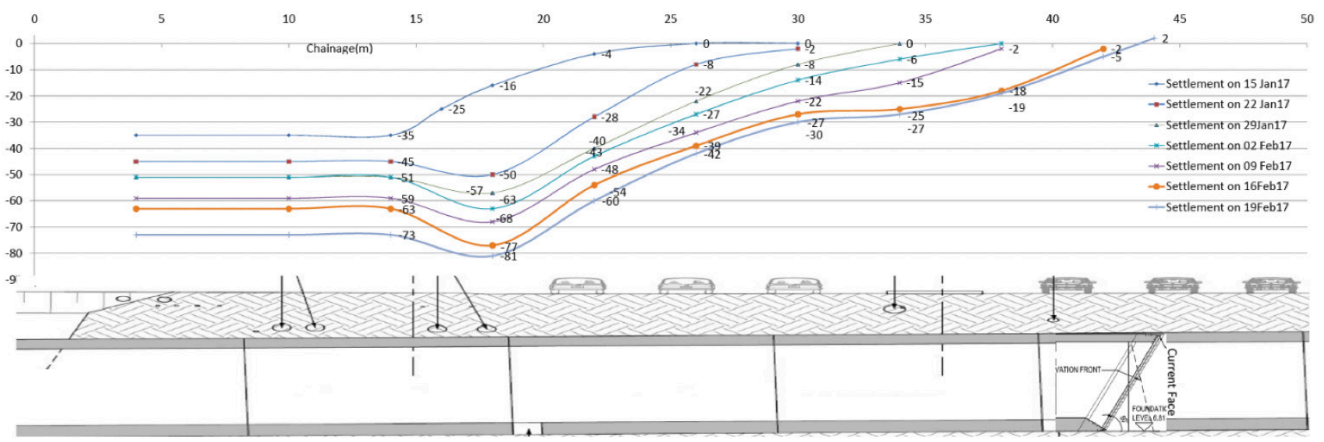

Figure 13: Measured surface settlements along subway 1

The over-excavation above the roof of the pre-cast boxes, was the main parameter for controlling the development and the magnitude of the surface settlements. The rock quality (moderate weathered Simsima limestone with Young's modulus stiffness of 1 GPa and GSI range of 45 to 55) proved competent with increased "stand up time" while the maximum actual over-excavation varied between $50 \mathrm{~mm}$ and $100 \mathrm{~mm}$.

\section{CONCLUSION}

Despite the tight and challenging schedule constraints and the low cover, the box pushing operations were concluded successfully and the settlements and ground deformations were within the acceptable levels. It was remarkable to observe the behavior of the rock mass for the unsupported length. Through the application of the box pushing construction method, there was no disturbance and negative impact on the high traffic volume and the construction works were completed prior to the contractual milestone. 


\section{ACKNOWLEDGEMENTS}

The authors would like to thank Qatar Rail and ALYSJ JV for their permission to publish this article.

\section{REFERENCES}

EN (1991-1-2004). Design of Concrete Structures.

Qatar Railways Company, Employers Requirements. 